\title{
Leukaemia and Sellafield: is there a heritable link?
}

\author{
E Janet Tawn
}

\begin{abstract}
The demonstration of a statistical association between paternal preconceptional irradiation and childhood leukaemia appeared to provide a satisfactory explanation for the excess of cases in the village of Seascale, close to the Sellafield nuclear installation, and became the basis of two legal claims for compensation. In the ensuing scientific debate the biological plausibility of a causal interpretation of this association focused on the heritability of leukaemia and a comparison of the genetic risks implied by this finding with current information on the induction of genetic damage by irradiation. After a wide ranging review of the mechanistic issues it is concluded that there is no genetic basis for a causal relationship and this, together with recent appraisals of epidemiological studies, suggests that the association between childhood leukaemia and paternal preconceptional irradiation exposure is most likely to be a chance finding.
\end{abstract}

(f Med Genet 1995;32:251-256)

In 1984 the Independent Advisory Group chaired by Sir Douglas Black confirmed a media report of an excess of childhood leukaemia in Seascale, a village near the Sellafield nuclear installation in West Cumbria operated by British Nuclear Fuels plc. ${ }^{1}$ A leukaemia and lymphoma case control study was recommended and in $199 \mathrm{C}$ Gardner et $a l^{23}$ reported the results on cases born and diagnosed in West Cumbria while under 25 years of age during 1950-1985. This became known as the Gardner Report. The most notable finding was a statistical association between relatively high levels of paternal preconceptional irradiation (ppi) received occupationally at Sellafield and the incidence of leukaemia (and leukaemia plus non-Hodgkin's lymphoma (NHL)) in their offspring. A 6 to 8-fold increased risk of childhood leukaemia was observed in the children of fathers who had received either a total recorded dose of external radiation before conception $>100 \mathrm{mSv}$, or $>10 \mathrm{mSv}$ in the six months before conception. Examination of the paternal preconceptional doses associated with the five
Seascale cases in the study led the authors to suggest that ppi could effectively explain the excess of cases in the village and the casecontrol study had therefore apparently achieved its objective. The causal hypothesis put forward to account for this association suggested that childhood leukaemias were the result of radiation induced sperm mutations which manifested themselves in first generation progeny. The implications of this hypothesis were commented on at the time. ${ }^{4-10}$ Attention was drawn to the lack of evidence in support of leukaemia having a strong heritable component and, in contrast, to the considerable evidence in favour of a somatic aetiology. Reference was also made to the discrepancy between the implied genetic risks derived from the Gardner Report and the risks generated by the International Commission on Radiological Protection (ICRP). ${ }^{11}$

Previous examination of the somatic risks associated with Sellafield discharges had not been able adequately to explain the excess of leukaemias ${ }^{12}$ and, despite the misgivings expressed by many scientists in the fields of human genetics and radiobiology, Gardner's hypothesis apparently offered an attractive explanation of the Seascale cases and became the basis of two claims for compensation against British Nuclear Fuels plc. The two cases, an infant who died of acute leukaemia aged 10 months (patient A) in 1962 and a non-fatal NHL diagnosed in a young woman at 23 years (patient B) in 1988, were heard concurrently before a single judge, with the court sitting for 90 days over the period October 1992 to June 1993. Evidence was held in five tranches; occupational dosimetry, environmental dosimetry, medical, epidemiology, and genetics, and took the form of oral evidence supported by written reports which had been mutually exchanged before the trial. The total preconceptional occupational radiation doses of both fathers were reassessed and agreed for the purposes of the litigation as being $530 \mathrm{mSv}$ and $233 \mathrm{mSv}$ respectively. Doses received by the fathers shortly before conception were also agreed, but discussions centred upon the accumulative preconceptional dose because it was with this dose that the epidemiological association was stronger. The medical evidence proved non-controversial and following a review of the diagnostic details it was agreed that patient $\mathrm{A}$ was a case of infant null acute 
lymphoblastic leukaemia (ALL) and patient B a case of non-endemic (sporadic) Burkitt's lymphoma. The genetics occupied approximately one third of the time in court. A report of how the witnesses presented the evidence in all the areas has been produced ${ }^{13}$ and this review will concentrate only on the key points generated by the issues loosely defined as genetics.

In presenting their evidence the plaintiffs contended that the statistical association between leukaemia and ppi was itself sufficien for their purposes. The defendants, however, were of the opinion that the proposed causal mechanism had to be a biologically acceptable explanation of the epidemiological findings before it could be applied to the two cases before the court. In exploring the plausibility of Gardner's hypothesis, evidence heard under the broad heading of genetics covered human genetics, leukaemia aetiology, virology, radiobiology, and the development of genetic risks. Details of the studies of the children of the Japanese atomic bomb survivors were included primarily in the section of evidence covering epidemiology but will be mentioned here. The evidence addressed two fundamental issues: the heritability of leukaemia, and the risks implied by the association of childhood leukaemia with ppi in comparison with current information on the induction of genetic damage by radiation.

Evidence for a heritable component in leukaemia was drawn from the recognition that there exist a number of well defined recessively inherited syndromes (for example, ataxia telangiectasia and Fanconi's anaemia), characterised by DNA repair deficiency and lack of immunocompetence, in which leukaemia is one of a number of clinical endpoints. In addition leukaemia is one of a range of malignancies, although not the most common, seen in families with the Li-Fraumeni syndrome. Such cases are rare and in any event the Seascale cases identified by Gardner, and the two cases before the court, did not fit the criteria of being part of a wider syndrome. It was accepted that to date no gene has been identified which having undergone mutation can be inherited and produce leukaemia as the only endpoint.

Although evidence in favour of an inherited component is sparse there is, in contrast, considerable evidence which argues against an inherited predisposing gene in the vast majority of leukaemias. Studies of childhood cancers in different ethnic groups living in Britain have shown that whereas racial incidence figures are maintained for cancers with a known heritable component, for example, retinoblastoma and Wilms' tumour, the incidence of leukaemia is associated with country of residence rather than ethnic origin, indicating environmental rather than heritable determinants. ${ }^{14}$ Leukaemia incidence in offspring of survivors of the disease ${ }^{15-17}$ and sibs ${ }^{18}$ provide little, if any, evidence of heritability. The absence of any strong evidence from consanguinity studies would suggest that the vast majority of childhood leukaemias are not associated with a single recessive gene and the lack of a paternal age effect would seem to rule out an inherited dominant gene, at least, with any significant level of mutability. Nevertheless a survey of registers and publications can produce family clusters. Felix et $a l^{19}$ reported a series of such families in the USA, in particular the occurrence of childhood ALL in a mother and son. There was, however, agreement that this was a not unexpected finding given the size of the population.

Perhaps the most important data are those relating to leukaemia in monozygotic twins. Although concordance has been reported, in the main this is confined to leukaemias in the first year of life and is attributable, not to an inherited mutation, but to events occurring in one twin with the subsequent transfer to the other twin in utero. ${ }^{20}$ For infant leukaemia all steps toward malignancy occur in utero before transfer, whereas for leukaemia in later childhood, where concordance is extremely rare, the initiating genetic change may become established in both twins but then be followed by different postnatal events. Recently the molecular nature of the genetic change has been identified in three pairs of twins with infant null ALL. ${ }^{21}$ The somatic change in the HRX gene which characterises this type of leukaemia was unique to each pair thus supporting the theory of in utero origin in one twin with subsequent transplacental transfer to the other.

In exploring the possibility of an inherited leukaemia predisposing gene, comparisons were made with the known childhood malignancies in which tumour suppressor genes have been shown, for example, retinoblastoma and Wilms' tumour. These mutations are highly penetrant and the diseases exhibit well established familial patterns. However, even disorders associated with tumour suppressor genes of much lower penetrance, for example, familial breast cancer, exhibit familial patterns, albeit not as clear cut. The lack of familial patterns in childhood leukaemia could only be explained if the gene was invariably lethal and exhibited $100 \%$ penetrance. Even so, a high concordance would be expected in monozygotic twins.

Mutational changes associated with leukaemia have been identified by the presence of chromosomal rearrangements. It was recognised, however, that these changes are acquired somatic mutations seen only in the malignant cells and are not constitutional changes transmitted through the germline. Many such changes are associated with oncogene activation. Since activated oncogenes invariably act in a dominant manner their presence in the germ cell is most likely to be too disruptive for normal fetal development. ${ }^{22}$ Genetically engineered constructs of oncogenes with specific promoters have been introduced into the constitutional genome of transgenic mice and viability maintained, but such studies are aimed at studying the sequential interactions of tumour development and not heritability. ${ }^{23}$ Indeed when the bcr-abl gene was introduced together with its natural promoter, no viable offspring were produced. ${ }^{24}$ However, although it was agreed that the chromosome changes associated with oncogene activation 
would not be passed through the germline, the plaintiffs speculated on the existence of an earlier event predisposing to specific oncogenic rearrangements.

The issue of heritability concentrated on leukaemia/lymphoma in general and in the event it was recognised that any heritable component outside the recognised syndromes, if it exists at all, is extremely small, in the order of $5 \%$. More specific attention was also given to the aetiology of the diseases in the two cases before the court. The confirmation of the in utero origin of the rearrangement of the HRX oncogene, ${ }^{21}$ and the recognition that this occurs in the majority of cases of infant null ALL, was of particular relevance to case A. With reference to case $B$ it was acknowledged that the hallmark of Burkitt's lymphoma (BL), the $t(8 ; 14)$ resulting in myc oncogene activation, is a somatic event arising as an accident of the normal developmental process of immunoglobulin gene rearrangement. The second event in endemic BL is mediated by Epstein-Barr (EB) virus and although the co-factor fulfilling this role in non-endemic or sporadic BL is unknown it was agreed that this would also operate somatically. It was recognised that familial cases of $\mathrm{BL}$ have been reported in males with $\mathrm{X}$ linked immunodeficiency syndrome, ${ }^{25}$ a disorder characterised by a predisposition to EB related disease. There was no evidence, however, that case B had this or any other immunodeficiency disorder.

During the course of the trial the Gardner Report was subjected to considerable scrutiny and reanalysis. It became apparent that the association of ppi with leukaemia is essentially confined to Seascale and is thus applicable to only a small fraction of the children of the Sellafield workforce. In fact, there is no general excess of childhood leukaemia in the rest of West Cumbria. ${ }^{26}$ This being so, if Gardner's hypothesis provides the explanation for the excess cases, it would be expected that ppi doses would be concentrated in fathers of children born in Seascale. The suggestion was investigated and the results, now published, ${ }^{27}$ were made available to the court. All children born in Cumbria between 1950 and 1989 to a father employed at Sellafield by BNFL or the United Kingdom Atomic Energy Authority (UKAEA) before conception were identified and ppi doses were obtained for each employeechild pair. Eight per cent of the children were born to a mother resident in Seascale, but only $7 \%$ of the collective total ppi dose (and $7 \%$ of the collective dose of radiation received by fathers in the six months before conception) were associated with these Seascale births. The 774 births to Seascale residents had a total collective dose of 38 person-Sv whereas the 8174 born elsewhere in West Cumbria were associated with a total collective dose of 490 person-Sv. This dose distribution is not consistent with ppi as a risk factor for leukaemia, since on the basis of the association seen in Seascale far too few cases have occurred among the paternally exposed children in the rest of West Cumbria.

The epidemiological analyses also showed that the effect of ppi in Seascale is confined to those with paternal doses $>100 \mathrm{mSv}$. Of the 112 Seascale cases in this category five developed leukaemia and if all these were inherited, as Gardner's hypothesis suggests, then this gives a frequency of 1 in 20 . When all 774 births in Seascale associated with ppi are considered then the frequency becomes 1 in 150 . If the heritable component of childhood leukaemia in the general population is taken as $5 \%$ and the population incidence as 1 in 1500 then the background rate of inherited leukaemia becomes 1 in 30000 . The implication is a 200fold increase in a dominantly inherited disorder in the Seascale children associated with ppi, and if the effect is confined to those with doses $>100 \mathrm{mSv}$ the increase is 1500 -fold. Such an increase in heritable effects would be expected to manifest itself in a variety of adverse obstetric outcomes but no such effect has been observed in the Seascale population. ${ }^{2829}$ If this hypothesised radiation induced effect were operating and if the same rate of increase were applied to other dominantly inherited disorders, then an epidemic of genetic effects should be seen in Seascale. Moreover, if the children with ppi outside Seascale are considered then West Cumbria should be overwhelmed with genetic disease. As an example, a similar rate of increase applied to neurofibromatosis, which has a spontaneous mutation frequency of 1 in $10000,,^{30}$ would result in 15 expected cases in Seascale. In the rest of West Cumbria with 13 times the collective paternal preconceptional dose, and where 11 times the number of births are associated with ppi, $\simeq 190$ cases would be expected. The implications of the genetic risk derived from the findings of Gardner $e t a l^{2}$ have been recognised in the most recent report from the United Nations Scientific Committee on the Effects of Atomic Radiation (UNSCEAR) on hereditary effects of radiation. ${ }^{31}$ This concludes that since no epidemic of genetic diseases has been reported around Sellafield or other nuclear sites, it is highly unlikely that Gardner's conclusions are correct.

In support of a biological mechanism to explain the association between ppi and leukaemia, Gardner et al $^{2}$ drew attention to a series of experiments by Nomura on radiation induced transgenerational carcinogenesis in mice. Nomura has published a number of papers dating back to 1975 , most of which are referenced in a recent review. ${ }^{32}$ Although principally concerning lung adenomas, a raised incidence of leukaemia in the offspring of paternally irradiated mice has also been reported. The methodology has been criticised, ${ }^{33}$ of particular concern being the selection of controls and the apparent lack of independent matings for the heritability experiments. A recent study has failed to confirm Nomura's findings. ${ }^{34}$ In addition a lifespan study undertaken in Oak Ridge, USA in the 1960 s but only recently published showed no increase in tumour incidence in offspring of irradiated mice. ${ }^{35}$

In over 40 years of studying the 70000 offspring of the irradiated survivors of the atomic bombings of Hiroshima and Nagasaki no sig- 
nificant radiation related increases in any of the range of genetic endpoints have emerged. ${ }^{36}$ Because there is no direct evidence of the adverse effects of transmitted radiation induced mutations in exposed human populations risk estimates have been derived from mouse data. The International Commission on Radiological Protection (ICRP) ${ }^{11}$ apply risk estimates generated by the United Nations Scientific Committee on the Effects of Atomic Radiation (UNSCEAR) ${ }^{31}{ }^{37}$ using the doubling dose (indirect) method. This method relies primarily on murine data from specific locus experiments to derive a doubling dose of $1 \mathrm{~Sv}$ which is then applied to human incidence data. Although no adverse effects have been seen in Japan, recent re-evaluation has shown that the data are consistent with minimal doubling dose estimates of between 1.7 and $2.2 \mathrm{~Sv}$ for acute irradiation of the type experienced in Japan, and of 3.3 to $4 \cdot 4 \mathrm{~Sv}$ for chronic irradiation. ${ }^{38}$ In noting this, ICRP are of the view that the use of a doubling dose of $1 \mathrm{~Sv}$ for determining genetic risks from low dose rate low LET radiation in man is conservative. ${ }^{39}$ For first generation effects the risk for a reproductive population from $10 \mathrm{mSv}$ of low LET radiation for mendelian plus chromosomal disorders $\simeq 18$ per $10^{6}$ live births The background frequency of these disorders is 16300 per $10^{6}$ live births ( 10000 dominant, 2500 recessive, 3800 chromosomal). ${ }^{3137}$ During 1950-1989 a total of 9256 children were born in Cumbria to fathers occupationally irradiated at Sellafield. ${ }^{27}$ The collective ppi dose for this group is 539 person-Sv giving a mean dose of $58 \mathrm{mSv}$. Applying the current risk estimates gives an expectation of $\simeq 1$ excess case of mendelian plus chromosomal disorders in this population in addition to the $\simeq 150$ spontaneous cases. Any genetic effect in this population or in the subgroup of 774 children born to fathers with ppi in Seascale, where the dose profile is similar, will not be discernible against statistical fluctuations in the background rate.

The mutation rate implied by the Seascale findings should also be examined in relation to the considerable knowledge gained from the study of radiation induced mutations in experimental studies. In vivo murine studies have shown a mean mutation rate for the recessive mutations in the specific locus assay of $7.3 \times 10^{-6}$ per locus per Sv for low LET low dose rate irradiation rising to $21.9 \times 10^{-6}$ per locus per Sv for acute exposure with a 35fold range in sensitivity across the seven genes studied. ${ }^{4041}$ These genes, which may be particularly mutable, ${ }^{42}$ are 10 times more sensitive than dominant cataract mutations. ${ }^{43}$ Studies of somatic cells exposed in vivo and in vitro to a wide range of doses and dose rates have indicated mutation rates in the range of 1 to $65 \times 10^{-6}$ per locus per Sv. ${ }^{43-45}$ Focusing on Seascale, the collective ppi dose for the 774 children born to fathers with occupational radiation exposure is 38 person Sv and if the five leukaemia cases are attributed to this dose the implied mutation frequency is $132000 \times 10^{-6}$ per locus per Sv. The difference cannot be explained by postulating a number of genes with typical radiosensitivity (that is, 1 to
$10 \times 10^{-6}$ ) since this would imply that the majority of the functional genes in man, estimated as 50000 to 100000 , could mutate in the germline so as specifically to cause leukaemia in the subsequent offspring.

The discrepancy between the mutation rate implied by the Seascale findings and previous studies cannot easily be reconciled. Attempts to do this have focused mainly on new mechanisms of gene mutation which might respond differently to radiation. ${ }^{46}$ Although an association of fragile sites with leukaemia has been postulated no functional relationship has been shown. ${ }^{47}$ Furthermore, a study of cancer in families of leukaemia patients with chromosomal rearrangements in their malignant cells at the same apparent location as heritable fragile sites could find no evidence of hereditary predisposition. ${ }^{48}$ In any event diseases known to be associated with amplification of repeat DNA sequences at fragile sites, for example, fragile X, show discernible, if irregular, familial patterns. There is no evidence that radiation can induce fragile sites in germ cells or preferentially damage pre-existing heritable fragile sites. Any such effect, particularly on the scale needed to explain the Seascale findings, would have been observed in the offspring of the atomic bomb survivors. Transposon mediated mutation and imprinting also came under scrutiny, but while there is increasing recognition of the role of these mechanisms in spontaneous genetic disease there is no evidence of a radiation inducible effect. Further speculation centred round the dose response for low dose chronic irradiation. The influence of dose rate has been widely studied (BEIR V). ${ }^{49}$ For low LET radiation the effectiveness of a given dose tends to decrease with decreasing dose rate while for high LET radiation no dose rate effect is observed. Recent studies, particularly on somatic cells undergoing malignant transformation in vitro, have pointed to an inverse dose rate effect for high LET radiation. Results in such studies are heavily influenced by cell cycle kinetics $^{50}$ and in any event do not provide an explanation of the magnitude of the Seascale findings. In contrast, in vivo experiments on the irradiation of mice spermatogonia ${ }^{51}$ indicate that an inverse dose rate effect can only be shown at high doses and can be explained by a greater incidence of cell killing.

In exploring all these possibilities it is necessary to postulate mechanisms of germline mutation that are limited to certain leukaemia specific genes and furthermore an effect confined to only a subset of the offspring of Sellafield workers, born and diagnosed while resident in one village. Any suggestion, however, that the excess of leukaemia could be explained by interaction between a germline mutation and a specific "Seascale factor", possibly a virus, does not stand up to scrutiny. Since the initial germline mutation is necessary for the alleged second factor to interact with, the limiting factor must be the mutation rate. At the very least the incidence in Seascale must represent the mutation rate of a dominant gene with complete penetrance. If leukaemia only arises in some proportion of those with the 
initial germline mutation who subsequently encounter the right postnatal conditions, then of necessity this implies an even greater underlying mutation rate.

The two cases before the court did not fall readily into the excess of leukaemias associated with ppi in West Cumbria which analysis had shown was confined to those born and diagnosed in Seascale. Case A had been included in the Gardner Report and was the one case of leukaemia with a father having a ppi dose $>100 \mathrm{mSv}$ out of a total of 1588 children born in West Cumbria outside Seascale, a not unexpected frequency. Case B was not part of the Gardner Report having been diagnosed in 1988. Although resident in Seascale at the time of diagnosis, she had been born about $3 \mathrm{~km}$ away in a neighbouring village. It was therefore a subject of some debate whether the association seen in Seascale between ppi and leukaemia in offspring born in the village could be extended to her. In their original studies Gardner et $a l^{23}$ had carried out analyses for leukaemia and leukaemia and NHL combined but not for NHL alone. When this was done in the course of the trial it became apparent that the association with ppi was for leukaemia alone and did not extend to NHL.

The Honourable Mr Justice French delivered his Judgement in the High Court of Justice, London on 8 October $1993 .{ }^{52}$ Having reviewed all the evidence he concluded "In my judgement, on the evidence before me, the scales tilt decisively in favour of the Defendants and the Plaintiffs, therefore, have failed to satisfy me on the balance of probabilities that ppi was a material contributory cause of the Seascale excess or, it must follow, of (a) the leukaemia of - [case A] or (b) the NHL of - [case B]." "In the result there must be judgement for the Defendants."

The cause of the Seascale cluster remains unresolved. A recently published study by the Health and Safety Executive ${ }^{5354}$ confirmed that the association of ppi with leukaemia was restricted to the small minority of the children of the Sellafield workforce who were born in Seascale. This Seascale association is statistically incompatible not only with the lack of a significant relationship between leukaemia and ppi for children born in the rest of West Cumbria ${ }^{5354}$ but also with the negative findings of other studies using objectively determined doses. ${ }^{55}$ Although confirming an association with total preconceptional external irradiation, the Health and Safety Executive study failed to confirm the association between leukaemia and the dose of radiation received by fathers shortly before conception, either among Seascale born children or among those born in the rest of West Cumbria. This study also showed that there is no association between leukaemia and the cumulative preconception dose owing to internally deposited radionuclides, and that there is a negative association between ppi and childhood cancers other than leukaemia and NHL.

It has recently been shown that concentration on the Seascale born cases ignores a statistically significant excess of cases of leukaemia and
NHL diagnosed while resident in Seascale but not born in the village. ${ }^{56}$ This excess cannot be explained by paternal preconceptional occupational radiation exposure. Furthermore, examination of the Seascale born cases with ppi in the Gardner Report indicates two young children with an unknown subtype of ALL, one child with null ALL, one young child with AML, and a young adult with CML. ${ }^{57}$ This heterogeneity extends to the cases born outside but diagnosed in Seascale and must raise questions in respect of a common aetiology and causative mechanism. The association between leukaemia and ppi appears most likely to be a chance finding. ${ }^{20}$ The village of Seascale is unusual, both in its high concentration of people of high socioeconomic class ${ }^{28}$ and in the mobility of its population. ${ }^{53}$ This has led Doll ${ }^{58}$ to suggest that the most plausible explanation for the increased incidence of leukaemia/ lymphoma in the village is the hypothesis put forward by Kinlen ${ }^{59}$ which postulates an infective basis brought about by an increase in population mixing in previously isolated areas.

This review has concentrated on examining the biological plausibility of the heritable mechanism which Gardner et al proposed to explain the association between leukaemia and ppi. Although not covered here, considerable effort has also been spent in examining the epidemiological issues. ${ }^{55}$ In its most recent publication UNSCEAR reviewed the epidemiological studies concerning the incidence of leukaemia around nuclear sites, ${ }^{60}$ thus adding to the previous assessment of the genetic implications of Gardner's hypothesis. ${ }^{31}$ This latest report concludes: "A tentative explanation based on an association of childhood leukaemia and paternal exposure has largely been discounted following extensive investigations of the Sellafield area and elsewhere and because there is no sound genetic basis for this effect." I wish to thank Dr R Wakeford for helpful discussions on
epidemiology and Mrs L Buckland and Mrs A Poyner for preparing the manuscript. Additionally I acknowledge the conpreparing the manuscript. Additionally I acknowledge the contribution of many geneticists and radiobiologists to this debate, in particular Professor $\mathrm{H} \mathrm{J}$
E J Hall, and Dr P Selby.

1 Independent Advisory Group (Chairman: Sir Douglas Black). Investigation of the possible increased incidence of cancer in West Cumbria. London: HMSO, 1984.

2 Gardner MJ, Snee MP, Hall AJ, Powell CA, Downes S, Terrell JD. Results of case-control study of leukaemia and lymphoma among young people near Sellafield nuclear plant in West Cumbria. BMF 1990;300:423-9.

3 Gardner MJ, Hall AJ, Snee MP, Downes S, Powell CA, Terrell JD. Methods and basic data of case-control study of leukaemia and lymphoma among young people near Sellafield nuclear plant in West Cumbria. BMf 1990;300: 429-34.

4 Abrahamson S. Childhood leukaemia at Sellafield. Radiat Res 1990;123:237-8.

5 Evans HJ. Ionising radiations from nuclear establishments and childhood leukaemias - an enigma. BioEssays 1990; 12:541-9.

6 Narod SA. Radiation, genetics and childhood leukaemia. Eur $\mathcal{A}$ Cancer 1990;26:661-4.

7 Neel JV. Update on the genetic effects of ionizing radiation. IAMA 1991;266:698-701.

8 Sankaranarayanan $K$. Ionising radiation and genetic risks. IV. Current methods, estimates of risk of Mendelian disease, human data and lessons from biochemical and molecular studies of mutations. Mutat Res 1991;258:75-97.

9 Baverstock KF. DNA instability, paternal irradiation and leukaemia in children around Sellafield. Int $\mathcal{F}$ Radiat Biol 1991;60:581-95.

10 Sankaranarayanan $K$. Estimates of genetic risk of exposure to ionising radiation and their use in radiation protection the 1992 status. $\mathcal{F}$ Radiol Prot 1992;12:129-36. 
11 International Commission on Radiological Protection. 1990 Recommendations of the International Commission on Radiological Protection (ICRP Publication 60). Ann ICRP 1991;21:1-3.

12 Stather JW, Dionian J, Brown J, Fell TP, Muirhead CR. The risk of leukaemia in Seascale from radiation exposure. Health Phys 1988;55:471-81.

13 Wakeford R, Tawn EJ. Childhood leukaemia and Sellafield: the legal cases. $\mathcal{f}$ Radiol Prot 1994; 14: 293-316.

14 Stiller CA, McKinney PA, Bunch KJ, Bailey CC, Lewis IJ Childhood cancer in ethnic groups in Britain, a United Kingdom children's cancer study group (UKCCGG) study. Br f Cancer 1991;64:543-8.

15 Draper GJ. General overview of studies of multigeneration carcinogenesis in man, particularly in relation to exposure to chemicals. In: Napalkov NP, Rice JM, Tomatis L, Yamasaki $\mathrm{H}$, eds. Perinatal and multigeneration car cinogenesis. Lyon: International Agency for Research on

16 Hawkins MM, Draper GJ, Smith RA. Cancer among 1348 offspring of survivors of childhood cancer. Int 7 Cancer

17 Mulvihill JJ, Connelly RR, Austin DF, et al. Cancer in offspring of long-term survivors of childhood and adolescent cancer. Lancet 1987;ii:813-7.

18 Draper CJ, Heaf MM, Kinnier Wilson LM. Occurrence of childhood cancers among sibs and estimation of familia risks. $\mathcal{F}$ Med Genet 1977;14:81-90.

19 Felix CA, D'Amico D, Mitsudomi T, et al. Absence of hereditary p 53 mutations in 10 familial leukaemia pedigrees. F Clin Invest 1992;90:653-8.

20 Doll R, Evans HJ, Darby SC. Paternal exposure not to blame. Nature 1994;367:678-80.

21 Ford AM, Ridge SA, Cabrera ME, et al. In utero rearrangements in the trithorax-related oncogene in infant leukaemias. Nature 1993;363:358-60.

22 Weinberg R. Tumour suppressor genes. Science 1991;254 $1138-46$.

23 Adams JM, Cory S. Transgenic models of tumour development. Science 1991;254:1161-6.

24 Heisterkamp N, Jenster G, Kioussis D, Pattengale PK Groffen J. Human bcr-abl gene has a lethal effect on embryogenesis. Transgenic Res 1991;1:45-53.

25 Tibebu M, Polliack A. Familial lymphomas, a review of the literature with report of cases in Jerusalem. Leukaemia and Lymphoma 1990;1:195-201.

26 Draper GJ, Stiller CA, Cartwright RA, Craft AW, Vincen TJ. Cancer in Cumbria and in the vicinity of the Sellafield nuclear installation, 1963-90. BMF 1993;306:89-94

27 Parker L, Craft AW, Smith J, et al. Geographical distribution of preconceptional radiation doses to fathers employed at
the Sellafield nuclear installation, West Cumbria. BMf 1993;307:966-71.

28 Gardner MJ, Hall AJ, Downes S, Terrell JD. Followup study of children born to mothers resident in Seascale, West Cumbria (birth cohort). BMf 1987;295: 822-7.

29 Jones $\mathrm{KP}$, Wheater AW. Obstetric outcomes in West Cumberland Hospital: is there a risk from Sellafield? $\mathcal{F} R$ Soc Med 1989;82:524-7.

30 Huson SM, Compston DAS, Clark P, Harper PS. A genetic study of von Recklinghausen neurofibromatosis in southeast Wales. 1 Prevalence, fitness, mutation rate, and effect of parental transmission on severity. $\mathcal{F}$ Med Genet 1989 26:704-11

31 United Nations Scientific Committee on the Effects of Atomic Radiation. Sources and Effects of Ionizing Radiation (UNSCEAR 1993 Report). New York: United Nations, 1993.

32 Nomura T. Paternal exposure to radiation and offspring cancer in mice: reanalysis

33 Selby PB. Experimental induction of dominant mutations in mammals by ionizing radiations and chemicals. In: Kalter $\mathrm{H}$, ed. Issues and reviews in teratology. Vol 5 . New Kalter H, ed. Issues and reviews in
York: Plenum Press 1990:181-253.

34 Cattanach BM, Patrick G, Papworth D, et al. Investigation of lung tumour induction in BALB/CJ mice following paternal X-irradiation. Int $\mathcal{Y}$ Radiat Biol (in press)

35 Cosgrove GE, Selby PB, Upton AC, Mitchell TJ, Steel MH, Russell WL. Lifespan and autopsy findings in the first-generation offspring of X-irradiated male mice. Mutat Res 1993;319:71-9.

36 Neel JV, Schull WJ, eds. The children of atomic bomb survivors: a genetic study. Washington DC: National Academy Press,

37 United Nations Scientific Committee on the Effects of Atomic Radiation. Sources, effects, and risks of ionizing radiation (UNSCEAR 1988 report). New York: United Nations, 1988.

38 Neel JV, Schull WJ, Awa AA, et al. The children of parents exposed to atomic bombs: estimates of the genetic doubling dose of radiation for humans. Am 7 Hum Genet 1990; 46:1053-72.

39 Sankaranarayanan $\mathrm{K}$. Genetic effects of ionising radiation in man. Ann ICRP 1991;22:75-94.

40 Russell WL, Kelly EM. Mutation frequencies in male mice and the estimation of genetic hazards of radiation in man. Proc Natl Acad Sci USA 1982;79:542-4.

41 Russell WL, Russell LB. The genetic and phenotypic characteristics of radiation-induced mutations in mice. Radiat Res 1959; suppl 1:296-300.

42 Neel JV, Lewis SE. The comparative radiation genetics of humans and mice. Annu Rev Genet 1990;24:327-62.

43 Ehling UH. Genetic risk assessment. Annu Rev Genet 1991; 25:255-89.

44 Sankaranarayanan $K$. Ionising radiation and genetic risks. III Nature of spontaneous and radiation-induced mutations in mammalian in vitro systems and mechanisms of induction by radiation. Mutat Res 1991;258:75-97.

45 Thacker J. Radiation-induced mutation in mammalian cells at low doses and dose rates. Adv Radiat Biol 1992;16: $77-124$.

46 Cox $\mathrm{R}$. Transgeneration carcinogenesis: are there genes that break the rules? NRPB Radiol Prot Bull 1992;129:15-23.

47 Sutherland GR, Simmers RN. No statistical association between common fragile sites and non-random chromosome breakpoints in cancer cells. Cancer Genet Cymosome breakpoints

48 Mules EH, Testa JR, Thomas GH, Abbey H, Cohen BH. Cancer in relatives of leukaemic patients with chromosomal rearrangements at rare (heritable) fragile-site locations in th:

49 National Research Council. Health effects of exposure to low levels of ionizing radiation (BEIR V). Washington DC: National Academy Press, 1990.

50 Brenner DJ, Hall EJ. The inverse dose dose-rate effect for oncogenic transformation by neutrons and charged particles: a plausible interpretation consistent with published data. Int $\mathcal{F}$ Radiat Biol 1990;58:745-58.

51 Searle AG. Mutation induction in mice. Adv Radiat Biol 1974;4:131-207.

52 Reay $v$ British Nuclear Fuels plc; Hope $v$ British Nuclear Fuels plc (QBD: French J). Medical Law Reports 1994;5: $1-55$.

53 Health and Safety Executive. HSE investigation of leukaemia and other cancers in the children of male workers at Sellafield. Sudbury: HSE Books, 1993 .

54 Health and Safety Executive. HSE investigation of leukaemia and other causes in the children of male workers at Sellafield: and other causes in the children of male workers at Sellafield:
review of results published in October 1993. Sudbury: HSE review of results

55 Little MP, Charles MW, Wakeford R. A review of the risks of leukaemia in relation to parental pre-conception exposure to radiation. Health Phys 1995;68:299-310.

56 Kinlen LJ. Can paternal preconceptional radiation account for the increase of leukaemia and non-Hodgkin's lymphoma in Seascale? BMF 1993;306:1718-21.

57 Wakeford R, Tawn EJ, McElvenny DM, Binks K, Scott LE Parker L. The Seascale childhood leukaemia cases - the mutation rates implied by paternal preconceptional radiation doses. F Radiol Prot 1994;14:17-24.

58 Doll R. Epidemiological evidence of effects of small doses of ionising radiation with a note on the causation of clusters

59 Kinlen LJ. Epidemiological evidence for an infective basis in childhood leukaemia. Br $\mathcal{F}$ Cancer 1995;71:1-5.

60 United Nations Scientific Committee on the Effects of Atomic Radiation. Sources and effects of ionizing radiation (UNSCEAR Radiation. Sources and effects of ionizing radiation (UN
1994 Reports). New York: United Nations, 1994. 